\title{
Treatment of Hypertriglyceridemia: a Review of Current Options
}

\author{
M. VRABLÍK ${ }^{1}$, R. ČEŠKA ${ }^{1}$ \\ ${ }^{1}$ Third Department of Internal Medicine, First Faculty of Medicine, Charles University in Prague, \\ Prague, Czech Republic
}

Received September 21, 2015

Accepted October 5, 2015

\begin{abstract}
Summary
Hypertriglyceridemia is an important marker of increased levels of highly atherogenic remnant-like particles. The importance of lowering plasma levels of triglycerides (TG) has been called into question many times, but currently it is considered an integral part of residual cardiovascular risk reduction strategies. Lifestyle changes (improved diet and increased physical activity) are effective TG lowering measures. Pharmacological treatment usually starts with statins, although associated TG reductions are typically modest. Fibrates are currently the drugs of choice for hyperTG, frequently in combination with statins. Niacin and omega-3 fatty acids improve control of triglyceride levels when the above measures are inadequately effective. Some novel therapies including anti-sense oligonucleotides and inhibitors of microsomal triglyceride transfer protein have shown significant TG lowering efficacy. The current approach to the management of hypertriglyceridemia is based on lifestyle changes and, usually, drug combinations (statin and fibrate and/or omega-3 fatty acids or niacin).
\end{abstract}

\section{Key words}

Triglycerides • Diet • Statins • Fibrates • Ezetimibe • Omega-3 fatty acids $\bullet$ Niacin $\bullet$ Mipomersen $\bullet$ Lomitapide

\section{Corresponding author}

M. Vrablík, Third Department of Internal Medicine, First Faculty of Medicine, Charles University in Prague, U nemocnice 1, Prague 2, 12801, Czech Republic. E-mail: michal.vrablik@vfn.cz

\section{Introduction}

Hypertriglyceridemia was recognized as an independent risk factor of cardiovascular disease (CVD) more than two decades ago when Austin and co-workers published their summary paper on the topic (Austin et al. 1998). However, the role of elevated triglyceride (TG) levels in the pathogenesis of atherosclerosis has been called into question many times since then. This was particularly the case when a number of trials testing whether TG reduction translates into a reduction of CVD events yielded rather ambiguous results (reviewed by Sacks et al. 2010). Today, the focus of our attention has been driven towards TGs as markers of remnant-like particles (RLP). RLPs are heterogeneous lipoprotein species that are highly atherogenic and are primarily comprised of chylomicrons and VLDL particles and their remnants (Varbo et al. 2013). The plasma of patients with metabolic syndrome, insulin resistance, and type 2 diabetes is typically enriched with RLPs and it is believed that these are the most important lipoproteins of atherogenic dyslipidemia, which is an important component of residual CVD risk (Fruchart et al. 2014). Cholesterol being carried within the RLPs can be taken up by macrophages via scavenger receptors that are not down regulated by the excess of intracellular cholesterol and, thus, RLP-cholesterol contributes greatly to the formation of foam cells, which is a requisite cell type for the initial atherosclerotic lesion (Nordestgaard et al. 1995). RLP-cholesterol has been shown to be the most sensitive marker of risk in some recent studies and it correlates closely with the levels of both non-HDL-cholesterol and triglyceride concentrations (Varbo et al. 2013, Jørgensen et al. 2013). Moreover, as demonstrated by the Copenhagen group, the relative proportion of cholesterol being carried by RLPs gradually increases with rising TG levels (Fig. 1, according to Varbo et al. 2014.) 
Therefore, it is presently accepted that lowering TG levels can bring additional benefit and CVD risk reduction, particularly in the context of insulin resistance (Fruchart et al. 2008). In the following review, we shall summarize contemporary approaches to the management of hypertriglyceridemia and discuss the pros and cons of various treatment modalities.

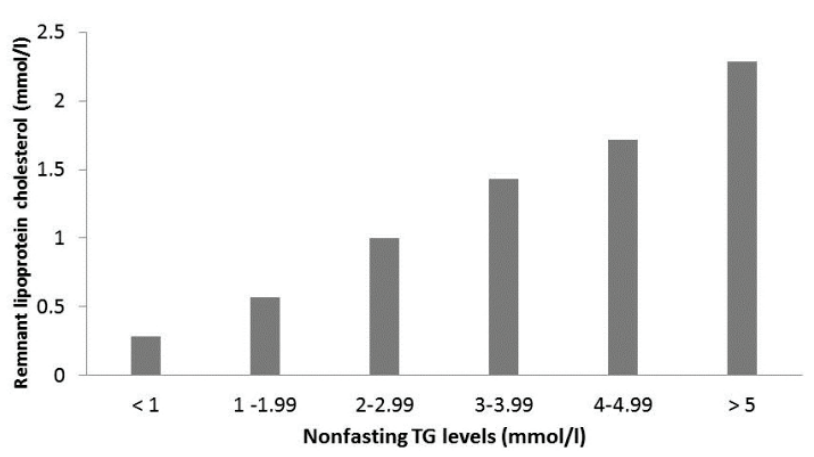

Fig. 1. Relative concentration of cholesterol in remnant-like particles as a function of increasing TG levels.

\section{Therapeutic lifestyle changes in the management of hypertriglyceridemia}

Diet is an effective way to lower elevated TG levels. All dietary changes that lead to weight loss in overweight or obese patients reduce hypertriglyceridemia; although, not all use the same mechanisms (Chapman et al. 2011). Decreased intake of dietary fats leads to lower amounts of intestinally-derived lipoproteins and, thus, lowers postprandial hyperlipidemia (Ooi et al. 2015). Reduced consumption of simple sugars (mono and diglycerides) helps improve insulin resistance and positively impacts hepatic production of TG-rich lipoproteins. In experiments comparing isocaloric doses of fructose and glucose, Havel's group demonstrated an interesting and significantly greater increase in insulin resistance (as well as in TG levels) associated with fructose consumption (Stanhope et al. 2015). Thus, not only the total intake of dietary carbohydrates, but also their types, are crucial regulators of postprandial and (to a lesser extent) fasting TG levels. Alcohol consumption should be reduced as alcohol (in a dose $>20 \mathrm{~g}$ /day) increases and prolongs postprandial hyperlipidemia and leads to overproduction of lipoproteins (both intestinal and hepatic) as well as delayed and decreased lipolysis and slower processing in liver cells (Klop et al. 2013). A summary of the effects of selected dietary components on TG levels is shown in Table 1.
Table 1. Recommended dietary interventions in hypertriglyceridemia.

\begin{tabular}{lc}
\hline Measure & $\begin{array}{c}\text { Magnitude } \\
\text { of effect }\end{array}$ \\
\hline $\begin{array}{l}\text { Reduce excessive body weight } \\
\text { Reduce alcohol intake }\end{array}$ & +++ \\
Reduce intake of mono- and & +++ \\
disaccharides & +++ \\
Reduce total amount of dietary & \\
carbohydrate & ++ \\
$\begin{array}{l}\text { Utilize supplements of omega-3 } \\
\text { polyunsaturated fat } \\
\text { Replace saturated fat with mono- or } \\
\text { polyunsaturated fat }\end{array}$ & ++ \\
\hline
\end{tabular}

Recommendations to increase physical activity represent a necessary condition in all patients presenting with hyperTG. Not only does regular physical activity decrease TG levels via activation of intraluminal lipoprotein lipase expression (thereby increasing intravascular lipolysis and clearance of TG-rich lipoproteins), but it also affects insulin resistance, decreases elevated glucose levels and improves overall cardiovascular fitness. Unfortunately, the benefits derived from physical activity are only temporary and disappear within a few weeks of its discontinuation (Plaisance and Fisher 2014, Gordon et al. 2014).

\section{Specific dietary recommendations to decrease elevated TG levels}

Pharmacological doses of omega-3 fatty acids (FAs) in the management of hypertriglyceridemia can be found on the boundary between pharmacological treatment and dietary recommendations. A number of studies have shown the impact of supplementation with fish oils or omega-3 fatty acids formulations on CVD risk; however, the results from these studies have been ambiguous (Vrablík et al. 2009). Nevertheless, the impact of gram-doses of omega-3 FAs has been shown to reduce elevated TG levels. Their role in the management of grossly elevated TGs has been demonstrated, accepted, and incorporated into guidelines (Reiner et al. 2011). However, a few unresolved issues remain; e.g. is there a role for omega-3 FAs in the context of moderate TG elevations (up to $5 \mathrm{mmol} / \mathrm{l}$ ), particularly in patients treated with statins. Current guidelines recommend 
omega-3 FAs as an adjunct to other therapies if their TG lowering efficacy is not satisfactory and hypertriglyceridemia persists (Reiner et al. 2011, Chapman et al. 2011).

\section{Pharmacological treatment}

Currently, there are several pharmacological options used for the reduction of increased TG levels and practically all available lipid lowering therapies have been shown to modify TG levels in the plasma. However, not all of them have clinically meaningful effects.

\section{Statins}

Statins reduce triglyceride levels by 10 to $20 \%$ from baseline values (Reiner 2010, Reiner et al. 2011). Figure 2 shows the TG lowering effects of selected statins as reported by major randomized clinical trials.

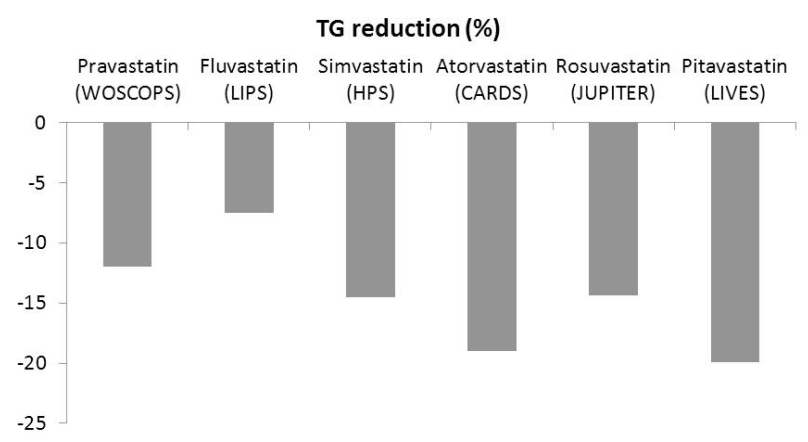

Fig. 2. Effects of statins on TG levels in selected randomized clinical trials.

The mechanism of the TG lowering effect has not been fully elucidated, but it seems to be independent of the LDL-receptor pathway. It may involve upregulation of VLDL uptake by hepatocytes, as well as a reduction in the production rate of VLDLs; these effects seem to be dependent on pre-treatment VLDL concentrations in the plasma (Sharma et al. 2014). Although statins represent the therapy of choice for the majority of patients, these agents are not typically indicated for the treatment of hypertriglyceridemia. However, given the above, TG lowering medications are frequently co-administered with statins in combination regimes.

\section{Fibrates}

Agonists of nuclear PPAR alpha receptors (i.e. fibrates) have been used in the treatment of hypertriglyceridemia and mixed dyslipidemias for many decades. These medications are now the most frequently used pharmacological option for the reduction of increased TG levels. Activation of the primary target of fibrates (i.e. PPARalpha receptors) results in a number of changes in intermediate metabolism ranging from an increase in the beta-oxidation of fatty acids to decreased secretion of VLDL from hepatocytes, and, most importantly, to activation of the lipoprotein lipase (LPL) gene together with suppression of transcription of the gene for apolipoprotein CIII (an inhibitor of LPL activity) (Shah et al. 2010). The described effects lead to increased clearance of TG-rich lipoproteins and their enhanced catabolism, thus resulting in significant reductions in plasma TG levels (Saha et al. 2007).

In long-term clinical trials, fibrates have been shown to reduce TG levels, on average, between 20-30\% (Fig. 3).

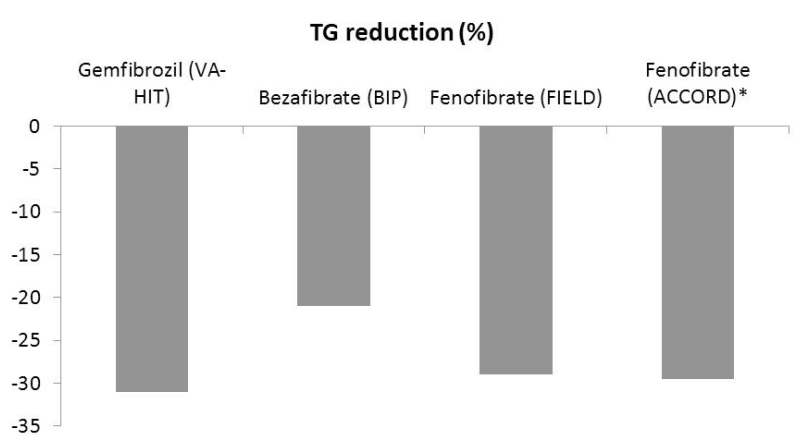

Fig. 3. Effects of fibrates on TG levels in selected randomized clinical trials.

Some smaller studies have suggested even more profound effects with reductions of $60 \%$ or more from baseline values. However, these dramatic reductions are most often seen in individuals with marked elevations of TG levels before treatment (McKeage and Keating 2011).

Recently, Ginsberg's group published an elegant study showing that fenofibrate significantly attenuates postprandial fluctuations of triglycerides and prevents significant increases in postprandial $\mathrm{TG}$ levels in susceptible individuals. Moreover, not only is postprandial hepatic production of VLDL suppressed by fenofibrate, but intestinal synthesis (as measured by assessment of apolipoprotein B48 concentrations in the plasma) is also decreased (Reyes-Soffer et al. 2013). These data further expanded our understanding of the multiple faces of fibrate action in lipoprotein metabolism. These postprandial effects are of particular importance given the most recent data from a Danish group indicating that postprandial plasma $\mathrm{TG}$ concentration is 
the best predictor of both coronary and cerebrovascular events risk, even outweighing LDL-cholesterol itself (Nordestgaard and Varbo 2014).

\section{Nicotinic acid}

Nicotinic acid (or niacin) has long been valued for its complex lipid modifying effects including marked decreases in plasma TG levels. In a dose-dependent manner, niacin was demonstrated to lower TGs by more than $40 \%$ and, in some cases, more than $50 \%$ from baseline values (Bodor and Offermanns 2008). Again, in those with marked elevations of TG concentrations, niacin had a greater effect compared to moderately hypertriglyceridemic patients. There are several effects of niacin that explain its well described lipid lowering efficacy. Niacin directly and noncompetitively inhibits hepatocyte diacylglycerol acyltransferase-2, a key enzyme in TG synthesis. The inhibition of TG synthesis by niacin results in accelerated intracellular hepatic apo B degradation and the decreased secretion of VLDL and LDL particles. Previous kinetic studies in humans and recent in vitro cell culture findings indicate that niacin mainly slows hepatic catabolism of apo A-I (vs. apo A-II), but not scavenger receptor BI-mediated cholesterol esters. Decreased HDL-apo A-I catabolism by niacin explains the increases in HDL half-life and concentrations of lipoprotein A-I HDL sub-fractions (Al-Mohassien et al. 2010). Surprisingly, free fatty acid mobilization from adipose tissue via the G proteincoupled niacin receptor has been suggested as a mechanism by which niacin decreases TGs; however, this pathway is likely to be a minor factor in explaining the lipid effects of niacin (Kammana et al. 2013).

Niacin has been widely tested in clinical studies both as monotherapy and in combination with other lipid lowering drugs. These studies have consistently demonstrated the positive impact of niacin on all lipoprotein classes including lowering lipoprotein (a). The magnitude of the TG lowering effect is dose dependent and, as with statins and fibrates, seems to be greater in patients with higher pre-treatment levels (Bruckert et al. 2010). Changes in plasma TG levels achieved in the largest clinical trials with niacin are summarized in Figure 4.

Despite a very long history of successful niacin use as a lipid modifying agent, most recent clinical studies have clearly demonstrated that there is no benefit to adding niacin to statin treatment (Boden et al. 2011). Moreover, in the HPS-THRIVE 2 study, in which a combination of niacin and laropiprant (an inhibitor of the prostaglandin D2 receptor that reduces flushing associated with niacin use) was used, investigators observed an increased risk of cerebrovascular events in the active treatment arm (Landray et al. 2014). Based on the latest data, niacin use is now more limited, but still has indications in special situations, such as severe hypertriglyceridemia refractory to alternative treatment options (Zeman et al. 2015).

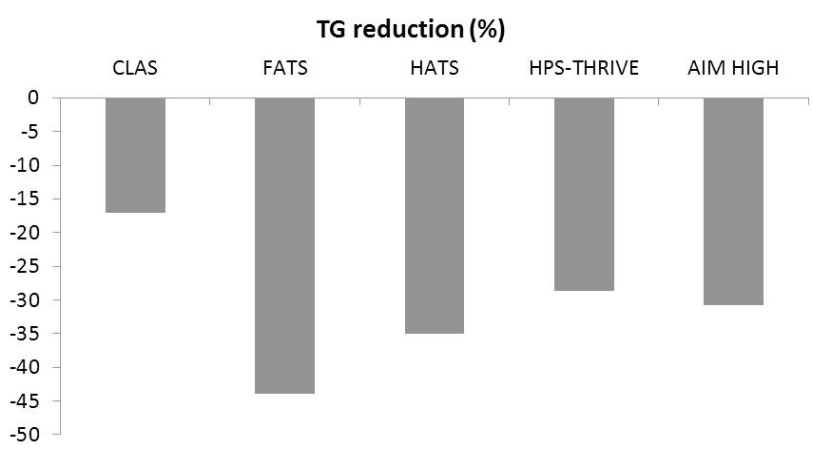

Fig. 4. Effects of niacin on TG levels in selected randomized clinical trials.

\section{Ezetimibe}

The effect of ezetimibe on plasma TG concentration is typically modest and its core indication remains cholesterol lowering as a component of combination regimes with statins. Ezetimibe acts as an inhibitor of the Nieman-Pick1-C1-like protein, found on the brush border of enterocytes, which blocks cholesterol absorption in the intestine. This leads to reduced influx of intestinal lipoproteins bound to cholesterol, which reduces the amount of cholesterol transported to liver cells and leads to greater expression of LDL-receptors on their surface, thus increasing clearance of LDL particles from the plasma. Given the interference of ezetimibe with the formation of intestinally-derived lipoproteins (as demonstrated directly in animal experiments), it is not surprising that it reduces fluctuations in postprandial lipemia (Naples et al. 2012). In addition, in the context of insulin resistance, ezetimibe administration leads to greater reduction of RLP-cholesterol than when insulin sensitivity is normal. Moreover, Tasake et al. showed elegantly that ezetimibe reduces visceral fat mass as well as production of adipocytokines in patients with metabolic syndrome (Tasake et al. 2012). Most recently, results from the IMPROVE-IT trial demonstrated the superior efficacy of ezetimibe in type 2 diabetics compared with the entire cohort, which might have been mediated by the positive 
changes in RLP metabolism and modulation of postprandial lipid metabolism (Cannon et al. 2015).

Therefore, in spite of the modest impact of ezetimibe on TG concentrations observed in clinical studies, this drug may well find a place in the treatment of mixed dyslipidemias characterized by elevations of not only non-HDL cholesterol but, most importantly, RLPcholesterol.

It is noteworthy that the ezetimibe safety profile is excellent and the medication is usually very well tolerated (Battaggia et al. 2015).

\section{Novel therapies and their impact of TG levels}

In recent years we have witnessed increased interest in novel options for the management of dyslipidemia, and research into lipid modifying agents has brought a number of new therapeutic options; some of these have already been registered, while others are currently close to entering clinical use.

A very special treatment option for severe hypertriglyceridemia associated with deficiency of lipoprotein lipase is the first gene therapy approved for use in humans; more specifically, an adenovirus associated vector (AAV- alipogene tiparvovec), which contains a variant of the $L P L$ gene displaying greater lipolytic activity compared to the common variant $\left(\mathrm{LPL}^{\mathrm{S} 447 \mathrm{X}}\right)$. Treatment is administered as a series of intramuscular injections after which $L P L^{S 447 X}$ gene expression can be detected in recipient tissues. Decreases in TGs as great as $40 \%$ from baseline values have been reported in some, but not all, treated individuals. However, expression of the transgene is temporary and TG levels typically rise again and reach pre-treatment levels within 26 weeks (Stroes et al. 2008). Despite this, subjects treated in clinical trials experienced significantly fewer episodes of acute pancreatitis compared to the period before treatment, and kinetic studies have demonstrated lower chylomicron TG content and their remnants, suggesting residual $L P L^{S 447 X}$ activity may persist. Most importantly, this treatment option represents the first gene therapy approved in humans and an important hope for otherwise difficult to treat patients with familial LPL deficiency (Bryant et al. 2013).

Lomitapide, a selective inhibitor of microsomal triglyceride transfer protein (MTTP), has been approved for the treatment of homozygous familial hypercholesterolemia; however, it also possesses significant triglyceride lowering properties (Kolovou et al. 2015). MTTP mediates lipidation of apolipoprotein B, which is a crucial step in the formation of many lipoprotein species that range from intestinally-derived chylomicrons to hepatic VLDL and LDL particles. Since this effect is not mediated by the LDL-receptor pathway, lomitapide also offers a unique treatment option for familial hypercholesterolemia homozygotes with little or no residual receptor activity (Raper et al. 2015). Given its mechanism of action, it is not surprising that lomitapide administration also results in a significant reduction in plasma TG levels, which may reach two thirds of the baseline values. MTTP inhibition can also be successfully used in the treatment of the abovementioned familial chylomicronemia. Sacks and co-workers reported on a case involving long-term lomitapide administration in a patient with familial chylomicronemia; they observed reductions in TG levels that exceeded $80 \%$. Unfortunately, the treatment was associated with development of liver steatosis that subsequently progressed to fibrosis; thus, the authors recommend that MTTP inhibition be considered only in patients with severe hypertriglyceridemia that triggers repetitive bouts of acute pancreatitis and is refractory to other treatment options (Sacks et al. 2014).

Mipomersen, an antisense oligonucleotide interfering with messenger ribonucleic acid during the translation and assembly of apolipoprotein B100, has been approved in the United States for the treatment of homozygous familial hypercholesterolemia. The effects of mipomersen parenteral administration observed in clinical trials were due to a reduction in the concentrations of all apoB100 containing lipoproteins (VLDL, IDL and LDL) by 25 to $65 \%$ (Gouni-Berthold and Berthold 2015). This effect is thought to be explained mostly by the blocking of translation and decreased production of lipoprotein species. This explanation supports findings that show that mipomersen administration was not associated with a marked decrease of hepatic VLDL production, but rather was associated with increased catabolism of both VLDL and LDL apoB (Reyes-Soffer et al 2014). This is in line with other previous findings confirming significant post-translational regulation of apoB secretion with variable levels of intracellular degradation of the protein (Olofsson and Borén 2012). Given the changes in VLDL and IDL particle metabolism induced by mipomersen, it is not surprising that treatment leads to significant changes in $\mathrm{TG}$ 
concentrations. Even in populations where mipomersen has found its primary indication (i.e. familial hypercholesterolemia, in which triglycerides typically are within normal range), administration of the oligonucleotide resulted in decreases between 15 and $25 \%$ (Najam and Ray 2015). A recent meta-analysis of eight trials with mipomersen concluded that the average decrease in TG levels with mipomersen reached $36 \%$ (Li et al. 2014). Since the medication reduces the concentrations of apoCIII, which is a potent inhibitor of VLDL and LDL clearance, as well as a powerful predictor of coronary artery disease risk, it might contribute to the observed significant TG lowering effect (Furtado et al. 2012).

The most intensively studied group of novel lipid modifying therapies is the monoclonal antibodies against proprotein convertase subtilisin kexin 9 (PCSK9). These agents block degradation of LDL-receptors (LDL-R) in lysosomes, increase re-circulation of LDL-R proteins and, thus, lead to an increased density of LDL-Rs on the surface of hepatocytes. This represents the primary mechanism by which PCSK9 inhibitors lead to substantial decreases in plasma concentrations of LDLcholesterol, which may exceed $70 \%$ from baseline values (Giugliano and Sabatine 2015). In clinical trials performed so far, there was a significant decrease in TG levels associated with the use of these new drugs; however, it seems rather modest compared to the magnitude of its LDL lowering efficacy (Fig. 5) (Li et al. 2015).

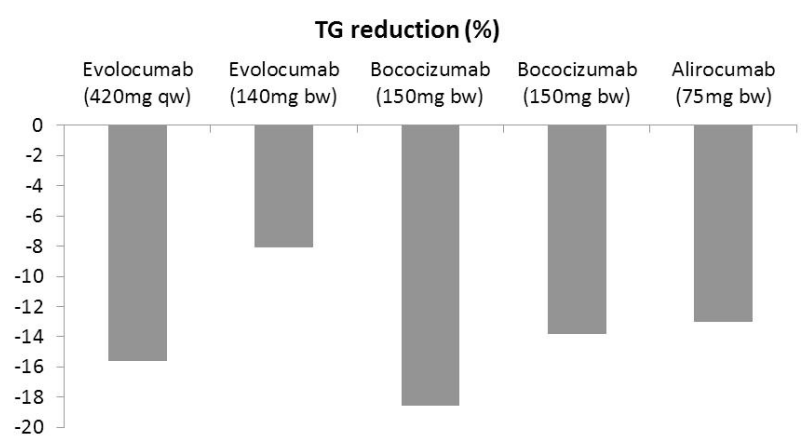

Fig. 5. Effects of PCSK9 inhibitors on TG levels in selected randomized clinical trials.

However, it should be noted that most of the subjects in the studies performed so far had low TG levels and, thus, it may well be the LDL receptor upregulation induced by the PCSK9 monoclonals might translate in more substantial TG lowering in hypertriglyceridemic individuals.

\section{Current approach to the management of hypertriglyceridemia}

Elevated levels of plasma TG are found in many different clinical situations, most of which are also associated with increased CVD risk. The management of hyperTG always relies on a combination of dietary and lifestyle changes and, when increased TG levels persist, on combination pharmacotherapy. The 2011 EAS/ESC guidelines for management of dyslipidemia suggest a treatment algorithm for hyperTG management, which emphasizes exploitation of non-pharmacological measures and elimination of aggravating factors first and then initiation of pharmacological therapy (Fig. 6) (according to Reiner et al. 2011).

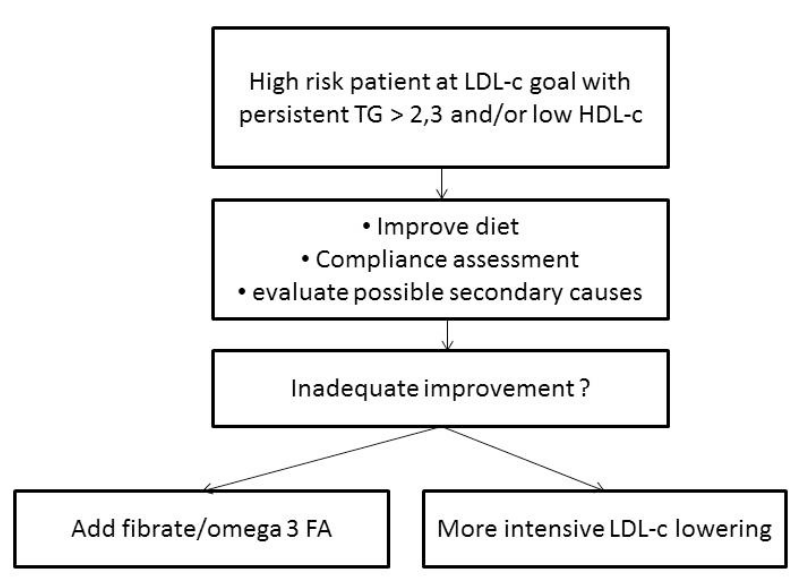

Fig. 6. Algorithm summarizing recommendations for management of patients with hypertriglyceridemia according to 2011 EAS/ESC guidelines.

Most patients with hyperTG, for whom pharmacological treatment is considered, also have high or very high CVD risk. Therefore, even in these individuals, statins are drugs of choice in an effort to help them reach their non-HDL cholesterol targets, and it is recommended that the more potent statins (e.g. atorvastatin, rosuvastatin, and pitavastatin) be used first. If hyperTG persists and triglyceride levels are greater than $2.3 \mathrm{mmol} / \mathrm{l}$ despite adequate statin doses, then combination therapy with a fibrate is recommended (Chapman et al. 2011, Reiner 2013). Given the safety profile and documentation from randomized clinical trials, fenofibrate is probably the preferred choice for combination regimes. As is consistent with other fibrate trials, the only random controlled trial testing the statin + fibrate combination (ACCORD) concluded that the combination seems to reduce CVD risk, but only in 
patients with high TGs (Ginsberg et al. 2010). Niacin, which was formerly recommended, has been mostly abandoned as the latest clinical trials have shown no benefit in the reduction of CVD risk; however, treatment may still be considered in the management of severe hyperTG. Combinations of statins and high doses of omega-3 FAs can also lead to a more significant reduction of triglycerides than statin monotherapy alone, but the impact of the combination on CVD outcomes remains questionable (Nestel et al. 2015). Smaller studies have reported even greater TG reductions through the use of triple therapy (statin-fibrate-omega-3 FAs) (Pirillo and Catapano 2015).

As summarized above, combinations with ezetimibe might improve metabolism of TG-rich lipoproteins. In statin intolerant patients with hyperTG, a combination of fenofibrate and ezetimibe might also be considered. In a smaller study by Farnier and co-workers, this combination resulted in a significantly greater proportion of patients reaching non-HDL cholesterol goals then either therapy alone; however, ezetimibe did not appear to add to the TG lowering effect of fenofibrate (Farnier et al. 2005). Nevertheless, ezetimibe finds its role in patients with mixed dyslipidemias, in whom it helps achieve non-HDL cholesterol targets and improve postprandial hyperlipidemia.

\section{Conclusion}

Hypertriglyceridemia is an important component of residual cardiovascular risk and is linked to the accumulation of highly atherogenic remnant-like particles. Its management starts with therapeutic lifestyle changes, which (given good adherence) represent an effective way to lower TGs. Pharmacological treatment of hyperTG in the context of increased CVD risk starts with a statin that should be complemented with fenofibrate when satisfactory control of hypertriglyceridemia cannot be achieved. Triple combinations using pharmacological doses of omega-3 FAs further improves hyperTG control. Some novel therapies (mipomersen and lomitapide) that are currently available for the treatment of homozygous familial hypercholesterolemia also have significant TG lowering properties; however, these should only be considered in rather special conditions of refractory hypertriglyceridemia associated with repetitive bouts of acute pancreatitis (e.g. LPL deficiency).

\section{Conflict of Interest}

There is no conflict of interest.

\section{Acknowledgement}

This work was supported by the project AZV MZČR: 15-28876A (Ministry of Health, Czech Republic).

\section{References}

AL-MOHAISSEN MA, PUN SC, FROHLICH JJ: Niacin: from mechanisms of action to therapeutic uses. Mini Rev Med Chem 10: 204-217, 2010.

AUSTIN MA, KING MC, VRANIZAN KM, KRAUSS RM: Atherogenic lipoprotein phenotype. A proposed genetic marker for coronary heart disease risk. Circulation 82: 495-506, 1990.

BATTAGGIA A, DONZELLI A, FONT M, MOLTENI D, GALVANO A: Clinical efficacy and safety of ezetimibe on major cardiovascular endpoints: systematic review and meta-analysis of randomized controlled trials. PLoS One 10: 1-24, 2015.

BODEN WE, PROBSTFIELD JL, ANDERSON T, CHAITMAN BR, DESVIGNES-NICKENS P, KOPROWICZ K, MCBRIDE R, TEO K, WEINTRAUB W, AIM-HIGH INVESTIGATORS: Niacin in patients with low HDL cholesterol levels receiving intensive statin therapy. N Engl J Med 365: 2255-2267, 2011.

BODOR ET, OFFERMANNS S: Nicotinic acid: an old drug with a promising future. Br J Pharmacol 153: 68-75, 2008.

BRUCKERT E, LABREUCHE J, AMARENCO P: Meta-analysis of the effect of nicotinic acid alone or in combination on cardiovascular events and atherosclerosis. Atherosclerosis 210: 353-361, 2010.

BRYANT LM, CHRISTOPHER DM, GILES AR, HINDERER C, RODRIGUEZ JL, SMITH JB, TRAXLER EA, TYCKO J, WOJNO AP, WILSON JM: Lessons learned from the clinical development and market authorization of Glybera. Hum Gene Ther Clin Dev 24: 55-64, 2013. 
CANNON CP, BLAZING MA, GIUGLIANO RP, MCCAGG A, WHITE JA, THEROUX P, DARIUS H, LEWIS BS, OPHUIS TO, JUKEMA JW, DE FERRARI GM, RUZYLLO W, DE LUCCA P, IM K, BOHULA EA, REIST C, WIVIOTT SD, TERSHAKOVEC AM, MUSLINER TA, BRAUNWALD E, CALIFF RM: Ezetimibe added to statin therapy after acute coronary syndromes. $N$ Engl $\mathrm{J} \mathrm{Med} \mathrm{372:} \mathrm{2387-2397,} 2015$.

CATAPANO AL, FARNIER M, FOODY JM, TOTH PP, TOMASSINI JE, BRUDI P, TERSHAKOVEC AM: Combination therapy in dyslipidemia: where are we now? Atherosclerosis 237: 319-335, 2014.

CHAPMAN MJ, GINSBERG HN, AMARENCO P, ANDREOTTI F, BORÉN J, CATAPANO AL, DESCAMPS OS, FISHER E, KOVANEN PT, KUIVENHOVEN JA, LESNIK P, MASANA L, NORDESTGAARD BG, RAY KK, REINER Z, TASKINEN MR, TOKGÖZOGLU L, TYBJ/ERG-HANSEN A, WATTS GF; EUROPEAN ATHEROSCLEROSIS SOCIETY CONSENSUS PANEL: Triglyceride-rich lipoproteins and high-density lipoprotein cholesterol in patients at high risk of cardiovascular disease: evidence and guidance for management. Eur Heart J 32: 1345-1361, 2011.

FARNIER M, FREEMAN MW, MACDONELL G, PEREVOZSKAYA I, DAVIES MJ, MITCHEL YB, GUMBINER B; EZETIMIBE STUDY GROUP: Efficacy and safety of the coadministration of ezetimibe with fenofibrate in patients with mixed hyperlipidaemia. Eur Heart J 26: 897-905, 2005.

FRUCHART JC, SACKS FM, HERMANS MP, ASSMANN G, BROWN WV, CESKA R, CHAPMAN MJ, DODSON PM, FIORETTO P, GINSBERG HN, KADOWAKI T, LABLANCHE JM, MARX N, PLUTZKY J, REINER Z, ROSENSON RS, STAELS B, STOCK JK, SY R, WANNER C, ZAMBON A, ZIMMET P: The Residual Risk Reduction Initiative: a call to action to reduce residual vascular risk in dyslipidaemic patient. Diab Vasc Dis Res 5: 319-335, 2008.

FRUCHART JC, DAVIGNON J, HERMANS MP, AL-RUBEAAN K, AMARENCO P, ASSMANN G, BARTER P, BETTERIDGE J, BRUCKERT E, CUEVAS A, FARNIER M, FERRANNINI E, FIORETTO P, GENEST J, GINSBERG HN, GOTTO AM JR, HU D, KADOWAKI T, KODAMA T, KREMPF M, MATSUZAWA Y, NÚÑEZ-CORTÉS JM, MONFIL CC, OGAWA H, PLUTZKY J, RADER DJ, SADIKOT S, SANTOS RD, SHLYAKHTO E, SRITARA P, SY R, TALL A, TAN CE, TOKGÖZOĞLU L, TOTH PP, VALENSI P, WANNER C, ZAMBON A, ZHU J, ZIMMET P: Residual macrovascular risk in 2013: what have we learned? Cardiovasc Diabetol 13: 26, 2014.

FURTADO JD, WEDEL MK, SACKS FM: Antisense inhibition of apoB synthesis with mipomersen reduces plasma apoC-III and apoC-III-containing lipoproteins. J Lipid Res 53: 784-791, 2012.

GINSBERG HN, ELAM MB, LOVATO LC, CROUSE JR 3RD, LEITER LA, LINZ P, FRIEDEWALD WT, BUSE JB, GERSTEIN HC, PROBSTFIELD J, GRIMM RH, ISMAIL-BEIGI F, BIGGER JT, GOFF DC JR, CUSHMAN WC, SIMONS-MORTON DG, BYINGTON RP. Effects of combination lipid therapy in type 2 diabetes mellitus. N Engl J Med 362: 1563-1574, 2010.

GIUGLIANO RP, SABATINE MS: Are PCSK9 inhibitors the next breakthrough in the cardiovascular field? J Am Coll Cardiol 65: 2638-2651, 2015.

GORDON B, CHEN S, DURSTINE JL: The effects of exercise training on the traditional lipid profile and beyond. Curr Sports Med Rep 13: 253-259, 2014.

GOUNI-BERTHOLD I, BERTHOLD HK: Mipomersen and lomitapide: two new drugs for the treatment of homozygous familial hypercholesterolemia. Atheroscler Suppl 18: 28-34, 2015.

JØRGENSEN AB, FRIKKE-SCHMIDT R, WEST AS, GRANDE P, NORDESTGAARD BG, TYBJÆRG-HANSEN A: Genetically elevated non-fasting triglycerides and calculated remnant cholesterol as causal risk factors for myocardial infarction. Eur Heart J 34: 1826-1833, 2013.

KAMANNA VS, GANJI SH, KASHYAP ML: Recent advances in niacin and lipid metabolism. Curr Opin Lipidol 24: 239-245, 2013.

KLOP B, Do REGO AT, CABEZAS MC: Alcohol and plasma triglycerides. Curr Opin Lipidol 24: 321-326, 2013.

KOLOVOU G, VASILIADIS I, GONTORAS N, KOLOVOU V, HATZIGEORGIOU G: Microsomal transfer protein inhibitors, new approach for treatment of familial hypercholesterolemia, review of the literature, original findings, and clinical significance. Cardiovasc Ther 33: 71-78, 2015. 
LANDRAY MJ, HAYNES R, HOPEWELL JC, PARISH S, AUNG T, TOMSON J, WALLENDSZUS K, CRAIG M, JIANG L, COLLINS R, ARMITAGE J, HPS2-THRIVE COLLABORATIVE GROUP: Effects of extendedrelease niacin with laropiprant in high-risk patients. N Engl J Med 371: 203-212, 2014.

LI C, LIN L, ZHANG W, ZHOU L, WANG H, LUO X, LUO H, CAI Y, ZENG C: Efficiency and safety of proprotein convertase subtilisin/kexin 9 monoclonal antibody on hypercholesterolemia: a meta-analysis of 20 randomized controlled trials. J Am Heart Assoc 4: e001937, 2015.

LI N, LI Q, TIAN XQ, QIAN HY, YANG YJ: Mipomersen is a promising therapy in the management of hypercholesterolemia: a meta-analysis of randomized controlled trials. Am J Cardiovasc Drugs 14: 367-376, 2014.

MCKEAGE K, KEATING GM: Fenofibrate: a review of its use in dyslipidaemia. Drugs 71: 1917-1946, 2011.

NAJAM O, RAY KK: Familial hypercholesterolemia: a review of the natural history, diagnosis, and management. Cardiol Ther 4: 25-38, 2015.

NAPLES M, BAKER C, LINO M, IQBAL J, HUSSAIN MM, ADELI K: Ezetimibe ameliorates intestinal chylomicron overproduction and improves glucose tolerance in a diet-induced hamster model of insulin resistance. $\mathrm{Am} \mathrm{J}$ Physiol Gastrointest Liver Physiol 302: G1043-G1052, 2012.

NESTEL P, CLIFTON P, COLQUHOUN D, NOAKES M, MORI TA, SULLIVAN D, THOMAS B: Indications for omega-3 long chain polyunsaturated fatty acid in the prevention and treatment of cardiovascular disease. Heart Lung Circ 24: 769-779, 2015.

NORDESTGAARD BG, VARBO A: Triglycerides and cardiovascular disease. Lancet 384: 626-635, 2014.

NORDESTGAARD BG, WOOTTON R, LEWIS B: Selective retention of VLDL, IDL, and LDL in the arterial intima of genetically hyperlipidemic rabbits in vivo. Molecular size as a determinant of fractional loss from the intima-inner media. Arterioscler Thromb Vasc Biol 15: 534-542, 1995.

OLOFSSON SO, BORÉN J: Apolipoprotein B secretory regulation by degradation. Arterioscler Thromb Vasc Biol 32: 1334-1338, 2012.

OOI EM, WATTS GF, NG TW, BARRETT PH: Effect of dietary fatty acids on human lipoprotein metabolism: a comprehensive update. Nutrients 7: 4416-4425, 2015.

PIRILLO A, CATAPANO AL: Update on the management of severe hypertriglyceridemia - focus on free fatty acid forms of omega-3. Drug Des Devel Ther 9: 2129-2137, 2015.

PLAISANCE EP, FISHER G: Exercise and dietary-mediated reductions in postprandial lipemia. $J$ Nutr Metab 2014: 1-16, 2014.

RAPER A, KOLANSKY DM, SACHAIS BS, MEAGHER EA, BAER AL, CUCHEL M: Long-term clinical results of microsomal triglyceride transfer protein inhibitor use in a patient with homozygous familial hypercholesterolemia. J Clin Lipidol 9: 107-112, 2015.

REINER Z: Combined therapy in the treatment of dyslipidemia. Fundam Clin Pharmacol 24: 19-28, 2010.

REINER Z: Managing the residual cardiovascular disease risk associated with HDL-cholesterol and triglycerides in statin-treated patients: a clinical update. Nutr Metab Cardiovasc Dis 23: 799-807, 2013.

REINER Z, CATAPANO AL, DE BACKER G, GRAHAM I, TASKINEN MR, WIKLUND O, AGEWALL S, ALEGRIA E, CHAPMAN MJ, DURRINGTON P, ERDINE S, HALCOX J, HOBBS R, KJEKSHUS J, FILARDI PP, RICCARDI G, STOREY RF, WOOD D: ESC/EAS Guidelines for the management of dyslipidaemias: the Task Force for the management of dyslipidaemias of the European Society of Cardiology (ESC) and the European Atherosclerosis Society (EAS). Eur Heart J 32: 1769-1818, 2011.

REYES-SOFFER G, NGAI CI, LOVATO L, KARMALLY W, RAMAKRISHNAN R, HOLLERAN S, GINSBERG HN: Effect of combination therapy with fenofibrate and simvastatin on postprandial lipemia in the ACCORD lipid trial. Diabetes Care 36: 422-428, 2013.

REYES-SOFFER G, DIONAIZOVIK M, JIMENEZ J, HOLLERAN S, RAMAKRISHNAN R, KARMALLY W, FONTANEZ N, OBUNIKE J, DONOVAN D, MOREY R, MITTEMAN R, CHIN W, BAKER B, GINSBERG HN: Treatment of healthy volunteers with mipomersen reduces levels of apoB 100-containing lipoproteins by increasing fractional removal of VLDL and LDL-apoB without reducing VLDL-apoB secretion. Poster presentation No. 696, 82 ${ }^{\text {nd }}$ EAS congress, Madrid, 2014. 
SACKS FM, CAREY VJ, FRUCHART JC: Combination lipid therapy in type 2 diabetes. N Engl J Med 363: 692-694, 2010.

SACKS FM, STANESA M, HEGELE RA: Severe hypertriglyceridemia with pancreatitis: thirteen years' treatment with lomitapide. JAMA Intern Med 174: 443-447, 2014.

SAHA SA, KIZHAKEPUNNUR LG, BAHEKAR A, ARORA RR: The role of fibrates in the prevention of cardiovascular disease--a pooled meta-analysis of long-term randomized placebo-controlled clinical trials. Am Heart $J$ 154: 943-953, 2007.

SHAH A, RADER DJ, MILLAR JS: The effect of PPAR-alpha agonism on apolipoprotein metabolism in humans. Atherosclerosis 210: 35-40, 2010.

SHARMA A, JOSHI PH, RINEHART S, THAKKER KM, LELE A, VOROS S: Baseline very low-density lipoprotein cholesterol is associated with the magnitude of triglyceride lowering on statins, fenofibric acid, or their combination in patients with mixed dyslipidemia. J Cardiovasc Transl Res 7: 465-474, 2014.

STANHOPE KL, MEDICI V, BREMER AA, LEE V, LAM HD, NUNEZ MV, CHEN GX, KEIM NL, HAVEL PJ: A dose-response study of consuming high-fructose corn syrup-sweetened beverages on lipid/lipoprotein risk factors for cardiovascular disease in young adults. Am J Clin Nutr 101: 1144-1154, 2015.

STROES ES, NIERMAN MC, MEULENBERG JJ, FRANSSEN R, TWISK J, HENNY CP, MAAS MM, ZWINDERMAN AH, ROSS C, ARONICA E, HIGH KA, LEVI MM, HAYDEN MR, KASTELEIN JJ, KUIVENHOVEN JA: Intramuscular administration of AAV1-lipoprotein lipase S447X lowers triglycerides in lipoprotein lipase-deficient patients. Arterioscler Thromb Vasc Biol 28: 2303-2304, 2008.

VARBO A, BENN M, TYBJÆRG-HANSEN A, JØRGENSEN AB, FRIKKE-SCHMIDT R, NORDESTGAARD BG: Remnant cholesterol as a causal risk factor for ischemic heart disease. J Am Coll Cardiol 61: 427-436, 2013.

VARBO A, BENN M, NORDESTGAARD BG: Remnant cholesterol as a cause of ischemic heart disease: evidence, definition, measurement, atherogenicity, high risk patients, and present and future treatment. Pharmacol Ther 141: 358-367, 2014.

VRABLÍK M, PRUSÍKOVÁ M, ŠNEJDRLOVÁ M, ZLATOHLÁVEK L: Omega-3 fatty acids and cardiovascular disease risk: do we understand the relationship? Physiol Res 58: S19-S26, 2009.

ZEMAN M, VECKA M, PERLÍK F, HROMÁDKA R, STAŇKOVÁ B, TVRZICKÁ E, ŽÁK A: Niacin in the treatment of hyperlipidemias in light of new clinical trials: has niacin lost its place? Med Sci Monit 21: 2156$2162,2015$. 